https://doi.org/10.18485/kud_kiaz.2019.ch39

\author{
Аида Юсифзаде \\ доктор политических наук, профессор, \\ заведующая кафедрой Международных отношений \\ Азербайджанского Государственного \\ Университета Языков (Баку, Азербайджан) \\ aidayusifzade@hotmail.com
}

\title{
ПРИОРИТЕТЫ ИНВЕСТИЦИОННОЙ ПОЛИТИКИ ВО ВНЕШНЕЭКОНОМИЧЕСКОЙ ДЕЯТЕЛЬНОСТИ АЗЕРБАЙДЖАНСКОЙ РЕСПУБЛИКИ
}

\section{SUMMARY}

Development of foreign economic multilateral relations of Azerbaijan, enlargement and deepening of cooperation with Western countries, attraction of foreign capital to oil and non-oil industrises which are specially prior and contributed to the development of highly profitable diversified economy of Azerbaijan. Here properly worked out conseptual basis of investment policy which has a decisive effect on a successful realising of the planned goals.In my opinion, growing stream of foreign investment to the economy of Azerbaijan, influences on strengthening of social-political stability both inside the country, and in the international relations and decreases danger of emerging of "frozen" armed interethnic conflicts.

Key words: oil, international relations, investment, economy.

Как известно, Азербайджан является страной с богатыми природными ресурсами. Их наличие и распространение связано со сложной историей геологического 
развития. На равнинных территориях в связи с наличием органических пород формируются нерудные полезные ископаемые, тогда как для горных территорий с магматическими породами характерны рудные полезные ископаемые. Территория Азербайджана издавна считалась одной из самой богатой нефтью территорий мира, хотя здесь расположены также значительные запасы природного газа, железа, золото, цинка, молибдена, каменной соли, йода, бромных скважинных вод, гипса, известняка, мрамора и других полезных ископаемых, а также гидроэнергетические ресурсы $[18,26]$

Транспортные коридоры, идущие с Востока на Запад и с Севера на Юг, ветви Великого Шелкового пути проходят именно через Азербайджан, что превращает страну в выгодный экономический центр, соединяющий большую часть торговых путей между Западом, Востоком и Югом. Благодаря выгодному расположению страны, наличию необходимых транспортных инфраструктур Азербайджан превращается в политический центр стратегического значения для всего Евразийского региона. Природные ресурсы, геополитическое и геоэкономическое расположение республики является тем условием, который устраивал иностранных предпринимателей. Согласно азербайджанских и ряд зарубежных авторов, преимущества Азербайджана для иностранных инвесторов и компаний заключается в следующих факторах:

- Плодородные условия для иностранных инвесторов (самый высокий в регионе показатель поголовных иностранных инвестиций напрямую, принятие юридическо-правовые решении для обеспечения инвестиционной деятельности);

- Быстро развивающаяся и открытая экономика (годовой рост ВВП в 26,4\%, годовой рост иностранного рыночного оборота в 19,8\%, уровень среднего импорта 5,7\% и т.д.);

- Широкие возможности в ненефтяном секторе (высокий рост в большинстве областей экономической дея- 
тельности за последние 5 лет: промышленный - 7,5, строительный- 3,8, рыночный- 3,5, транспорта и связи - 2,9, социальных услуг $-2,8$, сельскохозяйственный $-2,1$ раза, налоговые уступки производителям сельскохозяйственной продукции);

- Природные запасы: разновидные полезные ископаемые и плодородные земли;

- Выгодное стратегическое положение республики (непосредственный выход в Средней Азии и Каспийского бассейна, участие в международных коммерческих инициативах, в том числе Великий Шелковый путь, коридор Север-Юг, фактор расширяющейся Европы и присоединение к Новой Политике Добрососедства ЕС);

Развитие внешнеэкономических многосторонних связей, расширение и углубление сотрудничества со странами Запада, привлечение иностранного капитала в нефтяные и ненефтянные отрасли, которая является особо приоритетным и способствовало за короткий срок созданию высокорентабельной многоотраслевой экономики Азербайджана. Например, из всех иностранных инвестиций направленных на экономику страны в 1995-2011-х годах 25,5 млрд. доллара было направлено на развитие ненефтяного сектора, и 37,5 млрд. доллара - на развитие нефтяного сектора [17].

На этом вопросе важную роль играл правильно разработанная концептуальная основа инвестиционной политики, которая оказывает решающее влияние на успешную реализацию поставленных целей. Правительством Азербайджана при участии международных финансово - экономических организаций разработаны и осуществлены эффективные меры по либерализации внешнеэкономической деятельности, приватизации государственного имущества, достигнута стабилизация на микро и макроэкономическом уровне, а также создана благоприятная среда для привлечения в экономику местных и зарубежных инвестиций. 
На современном этапе инвестиционная деятельность Азербай-джанской Республике регулируется двумя законами. Первый закон, подтверждается Указом Президента Азербайджанской Республики за № 57 от 15 января 1992го года «Закон Азербайджанской Республики о защите иностранных инвестиций» и второй закон, подтверждается Указом Президента Азербайджанской Республики за № 952 от 13 января 1995-го года «Закон Азербайджанской Республики об инвестиционной деятельности» [6, 17]. Кроме этого, правительство Азербайджанской Республики подписало с рядом стран двусторонние соглашения об отмене двукратного налогообложения, поощрению и двусторонней защите инвестиций и присоединилась ряд конвенций и соглашений международного характера. Была осуществлена отмена всей ответственности связанной с конвертацией прибыли в иную валюту или с реинвестицией, на основе принципов рыночной экономики был сформирован единый валютный курс.

Эти мероприятия увеличили интерес иностранных инвесторов, международных финансовых учреждений и экономических организаций к Азербайджану. В процессе разработки, дополнении и реализации новых законов были уточнены и доработаны сущность и содержание конкретных понятий и терминов. Принятие парламентом республики более ста первоочередных законодательных актов ускорил ход экономических реформ. Наряду с законами «О защите иностранных инвестиций», «Об инвестиционной деятельности», были приняты законы «О банках и банковской деятельности», «О таможенной политике», «Об упрощении порядка регистрации совместных предприятий и их филиалов с участием отечественных юридических лиц и граждан» и другие, которые расширял дорогу зарубежным инвесторам вхождение в экономику республики. В 2010 году был принят Закон «Об инвестиционных фондах», расширяющий возможности для коллективных инвестиций [19]. Тем самым, иностранные инвесторы получили дополнительные гарантии. Особенно в 
нефтяном секторе, вероятность риска которого, очень высоко.

Инвестиционная политика Азербайджанской Республики определяет наиболее приоритетные направления капитальных вложений, от которых зависит повышение эффективности экономики, обеспечение наибольшего прироста продукции и национального дохода. Инвестиционный климат характеризует степень благоприятности ситуации, складывающейся в регионе, отрасли по отношению к инвестициям, которые могут быть сделаны. Практика показывает, что инвесторы проявляют интерес к странам, отличающимся политической и экономической стабильностью. Потен-циальные инвесторы знают, что надежность вложений и получение прибыли находятся в обратно непропорциональной зависимости. Чем надежнее страна в смысле инвестиций, тем меньше прибыли. Эксперты утверждают, что США - самая надежная страна для вложения инвестиций, и поэтому ту прибыль, которую получают инвесторы в Азербайджане за год от добычи нефти, для этого в США требуется не меньше 8-10 лет $[27,46]$. Этот фактор очень серьезно учитывается как зарубежными компаниями, которые вложили большой капитал в экономику нашей страны, так и инвестиционной политики Азербайджанской Республики, особенно в энергетическом секторе.

Согласно, статистических данных в Азербайджане зарегистрировано более 8 тыс. совместных предприятий, в которых представлен капитал свыше 60 стран. Их общий уставной фонд составляет около 10 млрд. долларов. Вообще объем иностранных инвестиций в экономику республики, скажем, за 1997 год достиг 1,3 млрд. долларов, что в 2,1 раза превысив уровень предшествующего года. Заметим, на настоящее время общий объем инвестиций, вложенных в национальное хозяйство, без учета нефтяного сектора переваливает за 38 млрд. долларов [31].

Подписание в 20 сентябре 1994 году с крупнейшими нефтяными компаниями мира «Контракта века», который 
явился историческим прорывом Азербайджана на мировой энергетический рынок и частью стратегии развития ее экономики. Параллельно были приняты также меры по наиболее эффективному развитию сотрудничества с международными организациями и иностранными компаниями. В итоге в 1995-1996 годах Международным Валютным Фондом и Мировым Банком были реализованы две программы, связанные с экономической реформой. При этом правительство руководствовалось опытом мировой практики, который свидетельствует, что сотрудничество и участие международных финансовых и экономических организаций в экономических реформах республики, является признаком стабильности и гарантии притоку иностранного капитала [2].

По оценкам британской нефтегазовой компании «ВР», доказанные запасы нефти в Каспийском регионе составляют около 30 млрд. тонн, или 19\% мировых доказанных запасов нефти, а доказанные запасы природного газа - 145 трлн. кубометров, или 45\% мировых доказанных запасов природного газа. Согласно прогнозам российской компании «Лукойл», к 2021-2024 годам добыча нефти на Каспии может достигнуть 200 млн. тонн в год, а природного газа - 270 млрд. кубометров [30] . По предварительным расчетам извлекаемые запасы нефти на месторождениях Азери, Чираг и Гюнешли составляли 511 млн. тонн, а впоследствии был установлен объем 1.072 млрд. тонн. Объективно разработанная, нефтяная стратегия привела к тому, что после «Контракта века» были подписаны еще 26 контрактов. С более чем сорок нефтяных компаний, которые представляют 19 стран, подписали с Азербайджаном новые контракты. [24].

В настоящее время Казахстан является одним из крупнейших производителей и экспортеров нефти в мире. Казахстан добывает 1,3 миллиона баррелей нефти в день, и экспортирует более 1 миллиона. В 2015 г. добыча достигла 3,5 миллиона баррелей нефти в день (150 
миллионов тонн в год), из которых 3 млн. баррелей экспортируется. Запасы казахстанской нефти оцениваются (предварительно) в 100-110 млрд. баррелей нефти и 141171 трлн. кубометров газа [10].

Для сравнения, если Азербайджан обладает 36-45 млрд. баррелей нефти, 46 трлн. куб. газа, то Туркменистан - 82 млрд. баррелей нефти, 257-314 трлн. кубометра газа. [10]. До настоящего времени в Азербайджанском секторе Каспия были вложены более 33 млрд. долларов инвестиции и добыто более 3,2 млрд. баррелей нефти. Еще 125 млрд. долларов было получено страной в виде прибыли от реализации проекта [24]. В 2016 году в нефтяной сектор Азербайджана было инвестировано 8,62 млрд. (57,8\%) против 7,16 млрд. в 2015 году (рост на 20,4\%), а 42,2\% (6,29 млрд.) было направлено на развитие ненефтяного сектора $(13,55)$.

Подписание «Нового контракта века» закладывал основу нового этапа нефтяной стратегии страны, это начало новой эры, дополнительную гарантию политической и экономической безопасности в регионе, вложение новых инвестиций в экономику Азербайджана, рост ВВП, новые рабочие места, увеличение дохода население и улучшение социального благосостояния. Напомним, что еще в 2007 году был сдан в эксплуатацию газопровод Баку-Тбилиси-Эрзурум (Южно-Кавказский газопровод), газ, добываемый в рамках первой стадии разработки месторождения «Шахдениз», стал экспортироваться в Грузию, Турцию и Грецию. А в 2012 году по инициативе Президента Азербайджана И.Алиева и Премьер-министра Турции Р. Т. Эрдогана в Стамбуле между двумя республиками подписан проект ТАНАП (Трансанатолийский газопровод). Год позже - в 2013 году консорциум «Шахдениз» избрал проект ТАП (Трансадриатический газопровод), соединяющий границы Турции с югом Италии, для поставок в Европу Азербайджанского газа, который будет транспортироваться по газопроводу ТАНАП. В настоящее время, продол-жается 
работа по прокладке трубопровода [24]. Данные проекты позволяют реализовать «Южный газовый коридор».

Согласно экспертизе, стоимость «Южного газового коридора» составляет около 40 млрд. долларов, включая 9,3 млрд. долларов на проект Трансанатолийского трубопровода (TANAP), 6 млрд. долларов - на проект Трансадриатического трубопровода (ТАР), а 23,8 млрд. долларов - на вторую стадию разработки месторождения «Шахдениз» и расширение Южнокавказского газопровода [23]. По другим оценкам экспертов прибыль от реализации ТАП и ТАНАП составит 42-48 млрд. долларов США [9].

Для привлечения иностранных инвестиций газовый потенциал Азербайджана играет немаловажный роль. В этом плане проект Южного газового коридора имеет особое значение. Проекта реализовали именно Азербайджан и Турция, хотя это была идея ЕС. Члены газового консорциума в 2013 году 17 декабря в Баку с участием официальных представителей различных стран заключили очередной договор о второй стадии разработки месторождение Шахдениз. Согласно договору в проект планировалось привлечь инвестиции на сумму приблизительно 23 - 28 млрд. долларов [28].

В турецком городе Эскишехир 12 июня 2018 года состоялась торжест-венная церемония по случаю сдачи в эксплуатацию Трансанатолийского газопровода - ТАНАП. В 2019 году ТАNAР объединится с ТАР и станет четвертым стратегическим источником газа для Европы [9]. В результате заинтересованности стран Южной Европы в азербайджанский газ, возник новый проект ИАП - Ион-Адриатический газовый провод, который доставит газ из Каспия в Албанию, Черногорию, Боснию, Герцеговину и Хорватию [3]. В целом, это не только новый источник иностранных инвестиций, а более на сто лет сотни млрд. долларов прибыли от реализации «Южного газового коридора» [25].

Таким образом, энергетические ресурсы Азербайд- 
жана будут поставляться на рынки Турции и Европы коротким и безопасным путем. Растущий поток иностранных инвестиций в экономику Азербайджана, на наш взгляд, с одной стороны влияет на укрепление социально-политической стабильности как внутри страны, так и в международных отношениях и уменьшает опасность возникновения «консервированных» вооруженных межнациональных конфликтов. Во-вторых, иностранные инвестиции способствует ускорению процесса включения экономики в мировое хозяйство, развитие эффективных интеграционных процессов. А в-третьих, иностранным инвестициям сопутствует приток прогрессивных технологий, обеспечивающих выпуск конкурентоспособной продукции. Однако, иностранные инвестиции, вложенные в основном нефтяной сектор экономики, действует в односторонней развитии страны, монополизируют инвестиционные ресурсы национальной экономики, что повышает стоимость и снижает объемы заемных средств, нефтяная и газовая промышленность являются более капиталоемкими, чем трудоемкими, тем самым вынуждает руководство страны еще более тщательно проводить энергетическую политику.

\section{Литература:}

Аббасбейли А.Н. Мировая политика. Баку: Нурлар, 2011, 584 с.

Аббасов Ч.М. Пути интеграции Азербайджана в мировую экономику. Баку: Элм, 2004, 263 стр. (на азерб.языке)

Азербайджан открывает дорогу энергетической безопасности Европы. Газ. Восток, 2017, 25 февраля (на азерб.языке) // http://www. sherg.az/site/id-27069/details\#.w11i7 dizbiu

Азербайджан продлил “Контракт века” еще на 25 лет: Подписан новый «Контракт века» https://kun.uz/ru/news/2017/09/18/azerbajdzanprodlil-kontrakt-veka-ese-na-25-let-podpisan-novyj-kontrakt-veka

Алиев М.Т. Проблемы формирования и развития Азербайджанской экономики. Баку: Маариф, 2001, 235 с. (на азерб. языке) 
Аллахвердиев, Г. Б. Регулирование инвестиционных процессов. Баку: Элм, 2003. 112 с. (на азерб.языке)

Бадалов А.М., Агаев А.М., Тагизаде С.Ж. Мировая экономика. Баку: Элм, 2006, 129 с. (на азерб. языке)

Байрамов А. Региональная экономическая интеграция: теория и практика. Баку: Элм, 1997, 168 с. (на азерб. языке)

В Турции запущен Трансанатолийский газопровод // https:// www.bfm.ru/amp/news/ 387236

Внешняя политика стран СНГ: учебник. М.: Изд. «Аспект Пресс», 2016, 700 c.

Гаджиев Ш.Т. Азербайджан на пути к мировому сообществу: стратегия внешнеэкономического развития. Киев: Наука, 2000, 286 с.

Гаджизаде Е., Багирзаде Е. Рейтинг Азербайджанской экономики в мире. Баку: Элм, 2011, 296 с. (на азерб.языке)

Годовой обзор состояния экономики и основных направлений внешнеэкономической деятельности Азербайджанской Республики в 2016 году. Баку: апрель 2017 года, 72 с.

Еще одна перспектива открывается важным газовым проектам Азербайджана в Европе. Газ. Баку вести, 2018, 28-30 июля (на азерб.языке)

Ибрагимов Ф.М. Иностранные инвестиции направленный на экономику Азербайджана и ее роль в возрождении национальной экономики. Баку: Изд. АЭУ, 2007, 196 с. (на азерб.языке)

Инвестиции в Азербайджане // https://ru.wikipedia.org/wiki/

Инвестиционная среда в Азербайджане // http://www.azerbaijans. com/content_1614_ru.html

Имрани 3. Т. Экономико-географическая характеристика территориальной организации Азербайджана. Б.: Изд. АЭУ, 2014, 232 с. (на азерб. языке.)

Исаев С.3. Правовое регулирование инвестиционной деятельности. Учебное пособие. Баку: Изд. АЭУ, 2011, 188 с. (на азерб.языке)

Конституционный Акт о государственной независимости Азербайджана. Б.: Азернешр, 1991, 23 с.

Микаилова С.М. Роль инвестиционной политики в обеспечении национальных интересов // Российское предпринимательство. М.: 2010, № 12, вып. 2(174), 168 с.

Миришли Ф.Р. Глобализация мировой экономики: феномен Азербайджана. Учебник. М.: ИСЭПиМ, 2008, 498 с.

Могерини: ЕС поддерживает проект газопровода «Южный газовый коридор». 6 февраля 2017 г.

Официальный сайт Президента Азербайджанской Республики // https://ru.president. az/azerbaijan/contract 
Oxu.az - Эксперт: Южный газовый коридор принесет Баку ... https://ru.oxu.az/ economy/259058

Постсоветские государства: 25 лет независимого развития. Сб. ст. в 2-х тт. / Отв. ред. А.Б.Крылов. Том 2. Южный Кавказ. М.: ИМЭMO РAH, 2017, $127 \mathrm{c}$.

Сулейманов Е. Экономика Азербайджана. Баку: Элм, 2010, 386 с. (на азерб.языке)

Шах-Дениз-2 почти готов - Новости-Азербайджан /novosti. az/ economy/6302.html

Экономические потерии Азербайджана в результате армянской агрессии // http://www.azerembassy.org.cn/rus/back_ecdam.html (на азерб.языке)

Энергетическая безопасность и энергетическая интеграция в Евразии в XXI веке: азиатский профиль / Под ред. Е. А. Телегина, Л. А. Студеникина. М.: Информ-Знание, 2006, 389 с.

http://www.1news.az/mobile/news/investicii-v-ekonomikuazerbaydzhana-za-22-goda-dostigli-233-mlrd

\section{РЕЗЮМЕ}

Развитие внешнеэкономических многосторонних связей Азербайджана, расширение и углубление сотрудничества со странами Запада, привлечение иностранного капитала в нефтяные и не нефтяные отрасли, которая является особо приоритетным и способствовала за короткий срок созданию высокорентабельной многоотраслевой экономики Азербайджана. И в этом вопросе важную роль играл правильно разработанная концептуальная основа инвестиционной политики, которая оказывает решающее влияние на успешную реализацию поставленных целей.

Растущий поток иностранных инвестиций в экономику Азербайджана, на мой взгляд влияет на укрепление социально-политической стабильности как внутри страны, так и в международных отношениях и уменьшает опасть возникновения “консервированных" вооружении межнациональных конфликтов.

Ключевые слова: нефть, международные отношения, инвестиции, экономика. 